TITLE:

\title{
Age categorization of conspecific and heterospecific faces in capuchin monkeys (Sapajus apella)
}

$\operatorname{AUTHOR}(S)$ :

Kawaguchi, Yuri; Kuroshima, Hika; Fujita, Kazuo

\section{CITATION:}

Kawaguchi, Yuri ... [et al]. Age categorization of conspecific and heterospecific faces in capuchin monkeys (Sapajus apella). Journal of Comparative Psychology 2019, 133(4): 502-511

ISSUE DATE:

2019-5-16

URL:

http://hdl.handle.net/2433/244806

\section{RIGHT:}

(c)American Psychological Association, 2019. This paper is not the copy of record and may not exactly replicate the authoritative document published in the APA journal. Please do not copy or cite without author's permission. The final article is available, upon publication, at: https://doi.org/10.1037/com0000185.; この論文は出版社版でありません。引 用の際には出版社版をご確認ご利用ください。; This is not the published version. Please cite only the published version. 


\section{Age Categorization of Conspecific and Heterospecific Faces in Capuchin Monkeys (Sapajus apella)}

\section{Yuri Kawaguchi ${ }^{1}$, Hika Kuroshima ${ }^{2}$ and Kazuo Fujita ${ }^{2}$}

${ }^{1}$ Department of Psychology, Kyoto University Faculty of Letters

${ }^{2}$ Department of Psychology, Kyoto University Graduate School of Letters

Author footnotes

Yuri Kawaguchi is now at Primate Research Institute, Kyoto University.

This research was supported by the Japan Society for the Promotion of Science Grantsin-Aid for Scientific Research (A) 25240020, (S) 16H06301. We thank J. R. Anderson for careful comments on the manuscript. We thank F. Tiago (University of São Paulo) and H. Jeremy for offering photos. We also thank H. Yusuke for his kind help with statistical analysis.

Correspondence concerning this article should be addressed to Yuri Kawaguchi, Primate Research Institute, Kyoto University, 41-2 Kanrin, Inuyama, Aichi 484-8506, Japan. Email: yuri.kawaguchi.09@gmail.com 


\section{AGE CATEGORIZATION IN CAPUCHIN MONKEY}

1

2 Across various species infant faces share various features referred to as "baby

3 schema” (Lorenz, 1943). Assuming that these features are indeed shared among

4 species, it is possible that non-human animals may perceive age information in

5 conspecific and heterospecific faces. We tested whether tufted capuchin monkeys

6 (Sapajus apella) would visually categorize age from faces. In Experiment 1, we trained

7 four monkeys to discriminate adult and infant faces of conspecifics using a symbolic

8 matching to sample procedure. We then tested whether their categorization transferred

9 to faces of other species (i.e. dogs and human). In Experiment 2, we trained another two monkeys on age categorization of heterospecific (human) faces and tested them with conspecific and dog faces, to assess whether conspecific age categorization in Experiment 1 was specific. In Experiment 3, the four monkeys from Experiment 1 were trained with human faces while the two monkeys from experiment Experiment 2 were trained with conspecific faces; we then tested all six monkeys with faces of dogs and other species including New World monkeys, Old World monkeys, apes and carnivores. During training the monkeys quickly learned to categorize adult and infant faces of both conspecifics and humans. However, age categorization failed to transfer to different species in the test phase in all three Experiments.

Keywords: capuchin monkey, age categorization, operant learning, baby schema, face recognition 


\section{AGE CATEGORIZATION IN CAPUCHIN MONKEY}

Recognizing the approximate age of other conspecifics is important for

appropriate social interactions. For example, recognizing whether another individual is

adult or not is crucial in reproductive contexts. Recognizing infants is also important for

many species including humans in which alloparenting is common. Behavior directed

toward infants and mature individuals usually needs to be different. Many primate

species show high tolerance of infants (Alley, 1980). One common infant signal or set of signals is the "baby schema," proposed by Lorenz (1943). The baby schema is a set of physical, especially facial features (e.g., large head, large eyes, protruding forehead, small nose and mouth) typical of infants in many species. In humans, such features (contained within "baby schema") induce the perceptions of cuteness and facilitate caretaking behavior (Alley, 1981, 1983b, 1983a; Borgi, Cogliati-Dezza, Brelsford,

Meints, \& Cirulli, 2014; Glocker et al., 2009; Sternglanz, Gray, \& Murakami, 1977).

Several studies have indicated that baby schema in other species' faces affect human perception (Borgi \& Cirulli, 2013; Borgi et al., 2014; Golle, Lisibach, Mast, \&

Lobmaier, 2013; Little, 2012). For example, Borgi et al., (2014) found that in 3-6-yearold children, cuteness scoring and gaze patterns were affected by baby schema of humans, dogs and cats, suggesting a common mechanism for recognizing baby schema

39 in human and animal faces.

40 The concept of baby schema - physical features likely shared across species leads to the question of how it affects facial perception in other animals. However, few experimental studies have addressed age-related recognition in nonhuman primates. In

43 one study (Sato, Koda, Lemasson, Nagumo, \& Masataka, 2012), when shown pairs of

44 visual stimuli Japanese macaques (Macaca fuscata) and Campbell’s monkeys 


\section{AGE CATEGORIZATION IN CAPUCHIN MONKEY}

45 (Cercopithecus campbelli) looked at images of infant Japanese macaques for longer than adult images. Similaly, barbary macaques (Macaca sylvanus) looked at images of newborn conspecifis longer than they looked at adults (Almeling, Hammerschmidt, Sennhenn-Reulen, Freund, \& Fischer, 2016). However, conspecific newborn faces did not capture the attention of two Japanese macaques (Koda, Sato, \& Kato, 2013). As far as we know, there is no study investigating whether nonhuman animals explicitly categorize individuals’ faces based on age.

The present study asked whether capuchin monkeys can form age categories from faces of conspecifics and heterospecifics. Like other primates, capuchin monkeys show strong attraction toward and tolerance of infants (Ottoni, de Resende, \& Izar, 2005). As capuchin monkeys are highly social and have a large repertoire of facial expressions (Fragaszy, Visalberghi, \& Fedigan, 2004), they should be sensitive to differences between faces. They have been shown to categorize individuals in photographs as ingroup or out-group (Pokorny \& de Waal, 2009) and to discriminate emotional facial expressions (Calcutt, Rubin, Pokorny, \& de Waal, 2017). We focused on face instead of

60 whole-body pictures because the face has multiple baby schema-related features. We

61 employed a symbolic matching-to-sample procedure using faces of adults and infants. It

62 is known that animals can easily learn to discriminate categories that are relevant to

63 their natural concepts. For example, Real, Iannazzi, Kamil, \& Heinrich (1984) trained

64 four blue jays (Cyanocitta cristata) to discriminate between leaf damage caused by palatable and unpalatable caterpillars. They reported that the birds quickly discriminated and generalized to new instances after learning only one pair of each category. If age 


\section{AGE CATEGORIZATION IN CAPUCHIN MONKEY}

category is ecologically relevant for capuchin monkeys, they should also learn to categorize individuals quickly.

We first trained four monkeys to discriminate between faces of adult and infant conspecifics, and then tested for generalization to human and dog faces (Experiment 1). We used both a familiar primate species (humans) and an unfamiliar nonprimate species (dogs) as test stimuli to see whether familiarity would affect performance. If speciesgeneral infantile features like baby schema exist in both primates and non-primates, and animals perceive this age-related information, they may do so even with unfamiliar species. To test whether age categorization for conspecifics was restricted, we conducted a second experiment in which two naive capuchin monkeys first learned to discriminate between adult and infant heterospecific (human) faces, after which we tested them with faces of dogs and conspecifics (Experiment 2). To test the possibility that monkeys may require training with multiple species stimuli to form a general age category, in Experiment 3 and trained the four monkeys from Experiment 1 on human stimuli and the two monkeys from Experiment 2 on conspecific stimuli. Then we tested all six monkeys for generalization using the same dog stimuli as previously, as well as stimuli from another eight species of New World monkeys, Old-World monkeys, apes and carnivores (see Table 1 for summary of overall flow). The capuchin monkey subjects see human adults (students and staff) every day, so they were highly familiar with human adults. They also see squirrel monkeys housed in the same room. By contrast, they have never been exposed to human infants, dogs or other species. If the monkeys naturally recognize conspecific age categories from facial features, they should easily learn the conspecific discrimination. Moreover, if this categorization 


\section{AGE CATEGORIZATION IN CAPUCHIN MONKEY}

90

92

93

94

95

96

98

ability operates across species, they should also learn the heterospecific discrimination and show transfer to facial stimuli from different species.

\section{Experiment 1}

\section{Methods}

\section{Subjects}

Four group-living adult tufted capuchin monkeys (Sapajus apella) participated: one 21-year-old adult male (“Heiji”), two multiparous adult females (“Zilla” and “Theta”, 21 and 19 years old, respectively), and a 12-year-old nulliparous female (“Zen”). All had participated in various noninvasive psychological experiments, including matching-to-sample tasks (e.g., Fujita, 2009; Hiramatsu \& Fujita, 2015). The monkeys were neither food- nor water deprived. They received vegetables, monkey chows, eggs and fruit at the end of testing each day. The experiment was approved by the Committee for the Animal Experiments of the Graduate School of Letters, Kyoto University (application 17-21).

\section{Apparatus}

The monkeys were trained and tested in an operant box $(45 \times 45 \times 45 \mathrm{~cm})$ with a touch-sensitive LCD monitor (Mitsubishi, TSD-CT157-MN, $1024 \times 768$ pixels) and a universal feeder (Biomedica, BFU310-P100) installed. Two levers and lever lights were attached below the monitor. The lever light was illuminated whenever the lever was available. Stimulus presentation, response detection, and food delivery were controlled by a customized program written in Microsoft Visual Basic 2010 Express on a personal 


\section{AGE CATEGORIZATION IN CAPUCHIN MONKEY}

114 noise masked external sounds during experimental sessions.

\section{Stimuli}

116 In the training phase we used 10 pairs of photos of unfamiliar adult and infant

117 conspecific faces. We also prepared four adult and infant face pairs of humans

118 (Japanese) and dogs (Labrador retriever) for the test phase. Most photos were obtained

119 from the Internet; others were taken by one of the authors or provided by colleagues.

120 Among the human adult stimuli there were two males and two females. The sex of most

121 of the depicted dogs, capuchins, and some human infants was unknown. As each species

122 has its own typical life history, controlling the age of infant stimuli is difficult. We

123 collected pictures of infants that appeared to be younger than weaning age (e.g., carried

124 by the mother). As we did not know the exact age of most of the stimulus individuals,

125 we prepared a questionnaire for 10 human volunteers (5 males, 5 females, mean age

12623.7 years, $S D=2.4$ ) to rate the age of all stimuli used in Experiments 1 and 2 on a 5-

127 point scale (1: “newborn”, 2:”infant”, 3:” toddler”, 4:”juvenile”, 5: “mature”). With one

128 exception, all infant monkey stimuli (average $=2.1, S D=0.37$ ) were rated younger than

129 all adult monkey stimuli (average $=4.26, S D=0.39$ ); the exception was judged as older

130 (mean rating: 4.3) relative to the other infant monkeys. However, as we knew that this

131 was a 4-month-old infant from information on the website of the zoo where it was born,

132 we included the image as an infant stimulus. All four infant human test stimuli were

133 scored younger (average $=1.68, S D=0.19$ ) than each of four adult human stimuli

134 (average $=4.8, S D=0.08$ ). All four puppy test stimuli were scored younger (average

$135=2.16, S D=0.67$ ) than each of four adult dog stimuli (average $=4.14, S D=0.23$ ). Using 


\section{AGE CATEGORIZATION IN CAPUCHIN MONKEY}

136 Adobe Photoshop CS6, we pasted each face into a square $(300 \times 300$ pixel $)$ with a 50\%

137 gray background. All stimuli were presented in grayscale (Figure 1).

\section{Procedure}

Monkeys were trained to discriminate between adult and infant conspecific faces

140 in a zero-delay symbolic matching-to-sample procedure (Figure 1). A sample stimulus appeared on the center of the monitor when the monkey pressed the illuminated lever

142 for 1 sec after a 3-sec ITI. Five touches on the sample resulted in its disappearance and

143 two geometric figures (“icons,” open square and striped square, $150 \times 150$ pixel)

144 appeared as comparison stimuli, one at each bottom corner of the monitor. One icon

145 corresponded to "adult" and the other to "infant," counterbalanced between subjects.

146 The left-right position of the icons was counterbalanced within a session. Each session

147 consisted of 100 trials. When the sample was an adult (or infant), touching the "adult"

148 (or infant) icon was reinforced by delivery of a small piece of food (apple or sweet

149 potato) via the universal feeder, accompanied by an electronic chime. Incorrect

150 responses were followed by a buzzer, no food reward and a 10-sec timeout during which

151 the house light was turned off. The monkeys were required to hold the lever down

152 during the trials; releasing it aborted the trial, which re-started. Our training and testing

153 procedures followed those in Adachi and Fujita's (2005) study of categorical

154 discrimination of human faces from the other body parts in pigeons.

155 Training phase. For each subject training started with a pair of conspecific adult

156 and infant faces randomly chosen from the set of 10 . To test robustness of the adult vs.

157 infant discrimination, whenever a subject scored higher than the $85 \%$ correct in 2

158 consecutive sessions we introduced a randomly chosen novel stimulus pair in probe test 8 


\section{AGE CATEGORIZATION IN CAPUCHIN MONKEY}

159

160

161

162

163

164

165

166

167

168

169

170

171

172

173

174

175

176

177

178

179

180

181

trials for two sessions. Sessions consisted of 32 probe trials and 68 baseline trials with learned stimuli. Rewards were delivered regardless of choice in probe trials but delivered only following correct choices in baseline trials. After two test sessions, we trained monkeys with their now-familiar stimuli along with the new ones. These aftertest training sessions consisted of 50 trials with the new stimuli and 50 with the old ones. Training continued until the monkeys performed at above $80 \%$ correct for the new stimuli for two consecutive sessions. We repeated this procedure until they learned 10 pairs of adult and infant faces. The order of introducing the new stimulus pairs was counterbalanced across subjects.

Test phase. We tested generalization of age-category discrimination to dog and human faces in all-reinforced probe test trials following consistently good performance for conspecific stimuli in further baseline sessions. In the baseline sessions, all of the learned capuchin monkey faces (10 adults and 10 infants) were randomly presented at the same frequency for 100 trials. The criterion was over $90 \%$ correct in total and over $80 \%$ for each adult and infant stimulus for two consecutive sessions. In generalization test sessions, we used 16 stimuli consisting of four different photos for each of four stimulus types (4 human adults, 4 human infants, 4 adult dogs, and 4 puppy). We randomly divided the stimuli into 2 equal sets; one set was used in the first generalization test and the other in the second test, each comprising 4 sessions as a block. Each test stimulus appeared four times per session. Sessions consisted of 100 trials (32 test and 68 baseline). We confirmed the baseline performance again between the first and the second test blocks. Each stimulus was presented on 16 trials in total.

\section{Statistical analysis}




\section{AGE CATEGORIZATION IN CAPUCHIN MONKEY}

We measured the number of sessions to reach criterion for new stimulus pairs

183

184

185

186

187

188

189

190

191

192

193

194

195

196

197

198

199

200

201

202

203

204

during the training phase. The number of correct responses in probe tests was analyzed using binomial tests with $50 \%$ as chance level.

To investigate whether age categorization transferred to novel species during the test phase, for each subject we used a logistic regression model with the number of “infant” responses as dependent variables, age category (adult, infant) as independent variable, and logit link function with binomial distribution as link function. We analyzed only the number of infant response because all the responses were either "infant” or “adult”. If monkeys recognized adult and infant correctly, then number of infant response should be significantly larger for infant stimuli than adult stimuli. For model fitting, we scored each adult stimulus as -1 and infant stimulus as 1 . We also performed a group analysis using a Generalized Linear Mixed Model (GLMM) with the same fixed effects (age category) and link function (logit link function with binomial distribution) as the logistic regression analysis and random effect of subject. Significance of the effect was tested by the likelihood ratio test with chi-square test (type II tests). All statistical tests were run on R statistical language and environment version 3.30.32 ( R Core Team, 2013) with “Ime4” (Bates, Mächler, Bolker, \& Walker, 2015) and “car” (Fox \& Weisberg, 2011) packages.

Results and Discussion

\section{Training phase}

In each probe test, response accuracies were significantly higher than chance level $(\mathrm{p}<0.05)$ on 5 pairs out of 9 in three subjects (Zen, Heiji and Theta), and on 6 pairs in 


\section{AGE CATEGORIZATION IN CAPUCHIN MONKEY}

205 Zilla, who scored above chance on all pairs after the 6th. These results showed that in

206 all subjects the acquired conspecific age categorization transferred to novel stimulus

207 pairs following training on a few exemplars; in other words, the monkeys did not have

208 to learn each exemplar anew. This result suggest that monkeys may have an age

209 category for conspecific faces.

\section{Test phase}

211 In the generalization test, a new species stimulus appeared in 128 trials (2 age

212 categories $\times 4$ faces $\times 16$ trials) in total. Figure 2 shows the number of "infant"

213 responses. In the dog condition, the logistic regression analyses revealed a significant

214 main effect of stimulus age in Zen ( $p=0.001$, odds ratio (OR) $=0.52$, Table 2$)$; she

215 selected the "infant” icon more frequently for adult stimuli than puppy stimuli. The

216 logistic regression intercept analysis showed that all the monkeys chose the "infant"

217 icon more frequently than "adult” (all: $p<.001$ ). This result is unlikely to reflect a bias

218 for a particular icon because the correspondence between age category and icon was

219 counterbalanced between subjects. We analyzed the number of infant responses for

220 adult dogs and puppies at group level using GLMM (see Table 3 for detail results).

221 "Infant" choices were significantly more frequent for adult dog faces than puppy faces

$222\left(\chi^{2}(1)=12.7437, p<.001\right)$, indicating a strong tendency to categorize adult dog faces as

223 “infant.”

224 In the human condition, the logistic regression analyses revealed no significant main effect of stimulus age in any monkey (Table2). The logistic regression intercept analysis showed that Heiji and Zen chose "infant” more frequently than "adult” (Heiji:

$227 p<.001$, Zen: $p=0.005$ ); the other two monkeys showed no bias (Theta: $p=0.078$, Zilla: 


\section{AGE CATEGORIZATION IN CAPUCHIN MONKEY}

228

229

230

231

232

233

234

235

236

237

238

239

240

241

242

243

$p=0.859)$. The GLMM group analysis of the number of “infant” responses also showed no significant difference between human adult and infant faces $\left(\chi^{2}(1)=0, p=1\right)$.

$<<<<<<<<<<<<<<<<<$ Figure 2 will be located around here $>>>>>>>>>>>>>>>>>>$

In summary, following training with conspecific stimuli, the monkeys

differentiated between adult dogs and puppies; however, they chose the infant icon more frequently than adult icon, and more so for adult dogs than puppies. This means that they were able to categorize adult dog and puppies on the basis of visual features, but the categorization was neither complete nor based on a species-general age category. Furthermore, the age category did not transfer to human stimuli. It is possible that the cues used by monkeys for categorization during the training were not available in the other species faces. In other words, features that differentiate between two age categories may not be shared by the three species. Another possibility is that the categorization formed through training was specific to own species. Specialized processing systems for own-species faces exist not only in humans (Dufour, Coleman, Cambell, Petit, \& Pascalis, 2004; Pascalis, de Haan, \& Nelson, 2002) but also capuchin monkeys (Dufour, Pascalis, \& Petit, 2006). To test this possibility, in Experiment 2, we trained monkeys first to discriminate between heterospecific (human) faces based on age, and then tested whether performance transferred to conspecific and heterospecific (dog) faces.

\section{Experiment 2}


AGE CATEGORIZATION IN CAPUCHIN MONKEY

\section{Method}

252

253

254

255

256

257

258

259

260

261

262

263

264

265

266

267

268

269

270

\section{Subjects}

Two adult male tufted capuchin monkeys participated: Zinnia and Pigmon (15 and 18 years old, respectively). Neither had participated in Experiment 1, but they also had various laboratory experiences including matching to sample tasks. Their housing conditions were the same as those described for Experiment 1.

\section{Apparatus}

We used the same apparatus as Experiment 1.

\section{Stimuli}

We used 10 adult and infant faces of humans (Japanese) for training. In the test phase, we used 4 capuchin and 4 dog (Labrador retriever) faces from each age category. All dog stimuli and most human and monkey stimuli came from those used in Experiment 1. All human infant stimuli (average $=1.82, S D=0.39$ ) were rated younger than human adult stimuli (average $=4.67, S D=0.21$ ). Apart from the exception mentioned in Experiment 1, the infant monkey test stimuli were scored younger (average $=1.96, S D=0.06)$ than the adult monkey stimuli (average $=4.45, S D=0.53$ ).

All the stimuli were the same size $(300 \times 300$ pixels $)$ and presented in grayscale.

\section{Procedure}

Training phase. We trained the monkeys on age-based discrimination of human faces using the same procedure as in Experiment 1. 


\section{AGE CATEGORIZATION IN CAPUCHIN MONKEY}

271

272

273

274

275

276

277

278

279

280

281

282

283

284

285

286

287

288

289

290

291

Test phase. After training, we tested for age categorization ability transfer to dog and capuchin monkey stimuli, using the same procedure as in Experiment 1.

\section{Statistical analysis}

We ran the same statistical analysis as in Experiment 1 except for the group analysis (GLMM).

\section{Result and Discussion}

\section{Training phase}

In probe tests, after the 4th pair the monkeys performed significantly above chance on age discrimination of all the novel pairs except Pigmon's 8th pair. Thus, they learned to categorize human faces according to age class and transferred this ability to novel human stimulus pairs, similar to the monkeys trained with capuchin faces in Experiment 1. The performance of the two monkeys was similar to that of the monkeys trained with conspecific faces in Experiment 1; monkeys can easily categorize adult and infant faces of not only conspecifics but also humans.

\section{Test phase}

In the generalization test, a new species stimulus appeared in 128 trials (2 age categories $\times 4$ faces $\times 16$ trials) in total. Figure 3 shows the number of "infant" responses. In the "dog” condition, the logistic regression analyses revealed no significant main effect of stimulus age in either subject (Pigmon: $p=0.101$, Zinnia: $p=0.594$, Table 4); the monkeys did not discriminate between adult dogs and puppies. The logistic regression intercept analysis showed that both subjects chose the "infant" 


\title{
AGE CATEGORIZATION IN CAPUCHIN MONKEY
}

292

icon more frequently than the "adult" icon (both: $p<.001$ ), the same result as in the dog condition in Experiment 1.

In the conspecific condition, the logistic regression analyses revealed a significant main effect of stimulus age for Pigmon $(p=0.031$, OR=1.49, Table 4) but not for Zinnia $(p=0.415)$. Although Pigmon discriminated according to age category, the logistic regression intercept analysis showed that he chose "adult" more frequently than the “infant” icon ( $p=0.013$, OR=0.63). By contrast, Zinnia chose the "infant” more frequently than the "adult” icon $(p<.001$, OR=3.02).

$<<<<<<<<<<<<<<<<<$ Figure 3 will be located around here $>>>>>>>>>>>>>>>>>>$ In Experiment 2, the monkeys failed to discriminate according to age category of either dogs or humans despite training on heterospecific stimuli. Therefore failure in generalization of the age category in Experiment 1 is not explained by specialized learning for own-species faces. Monkeys showed an “infant choice bias” for dog stimuli, as did the monkeys in Experiment 1. The categorization might not have transferred to other species in both Experiments because monkeys have formed an age category limited to training species. If so, training with multiple stimuli may be required to form a more general age category. Another possibility is that the three stimulus species did not shared age-related cues. Therefore in Experiment 3 we trained the monkeys with another species stimulus set and then tested for transfer of categorization to a variety of novel species.

\section{Experiment 3}

\author{
Method
}




\section{AGE CATEGORIZATION IN CAPUCHIN MONKEY}

\section{Subjects}

317 The six capuchin monkeys from Experiments 1 and 2 participated in Experiment 3.

\section{Apparatus}

319 We used the same apparatus as Experiment 1.

\section{Stimuli}

We used 10 adult and infant faces of humans and conspecific stimuli for training.

322 In the test phase, we used the same dog stimuli used in Experiments 1 and 2. For further generalization testing we prepared various species stimuli from four taxonomic groups including New World monkeys (white-headed capuchin monkeys, squirrel monkeys),

Old World monkeys (anubis baboons, Japanese macaques), apes (gorillas, chimpanzees) pixels) and presented in grayscale.

\section{Procedure}

330 Training phase. We trained the four monkeys from Experiment 1 on age-based

331 discrimination of human faces and trained the two monkeys from Experiment 2 on

332 discrimination of conspecific faces. The procedure was the same as in Experiments 1

333 and 2.

334 Test phase. After training, we tested if age categorization transferred to dog stimuli.

335 Generalization tests with the novel species were also conducted after confirming the

336 baseline performance. The procedure was the same as in Experiments1 and 2. 


\section{AGE CATEGORIZATION IN CAPUCHIN MONKEY}

\section{Statistical analysis}

We performed a group analysis on the number of “infant” responses using a Generalized Linear Mixed Model (GLMM) with age category (and species for the novel species test) as fixed effect, binomial distribution as link function, with random effect of subject.

\section{Result and Discussion}

\section{Training phase}

In each probe test of the training phase response accuracies of the monkeys trained with human stimuli were significantly higher than chance level on 6-9 pairs out of 9 (Theta: 6, Zen; 7, Zilla; 8, Heiji; 9). For the monkeys trained with monkey stimuli, response accuracies for Zinnia were significantly higher than chance on 8 pairs and for Pigmon on 5 pairs. As in Experiments 1 and 2, monkeys trained on human or monkey stimuli quickly transferred their acquired age categorization to novel stimulus pairs.

\section{Test phase}

Dog stimuli: The GLMM group analysis of the number of “infant” responses showed no significant difference between adult and infant faces $\left(\chi^{2}(1)=0, p=0.06\right.$, Table 3, Figure 4). Although we cannot conclude that the monkeys succeeded to differentiate adult dog and puppy faces, the opposite response (respond as "infant” to adult dogs) observed through Experiment 1 and 2 was disappeared.

Various species stimuli: We analyzed the number of infant responses for each of the four taxonomic groups at group level by using GLMM (Table 5). The monkeys made significantly more “infant” responses to infant stimuli than adult stimuli $\left(\chi^{2}(1)=14.78\right.$, $p<0.001)$. There was also a significant main effect of taxonomic stimulus group 17 


\section{AGE CATEGORIZATION IN CAPUCHIN MONKEY}

362

363

364

365

366

367

368

369

370

371

374

375

376

377

378

379

380

381

382

383

384

385

$\left(\chi^{2}(3)=20.48, p<.001\right)$. Multiple comparisons with Bonferroni correction revealed significant differences between "apes” and “carnivores”, and “apes” and "New World monkeys" (both $p<0.001$ ). Performance for ape stimuli was better than that for other stimuli (at least carnivores and New-world monkeys). One possibility is that physical difference between adult and infant faces of apes were more salient, but morphological study is required to confirm this. Another possibility is that cues used by monkeys in training were salient in the ape stimuli. In general, the monkeys differentiated between infant and adult stimuli, but "infant” responses continued to predominate (“infant choice bias”, Figure 5).

$<<<<<<<<<<<<<<<<<$ Figure 4, 5 will be located around here $>>>>>>>>>>>>>>>>>$ Given that the "infant choice bias” for adult dog stimuli disappeared and monkeys differentiated age category of various species stimuli, their generalization performance can be said to have slightly improved following training on a second species in Experiment 3. However, there was no evidence of formation of a species-general age category; nor did they transfer age categorization to faces of New World monkey, despite belonging to the same taxonomic group. This is consistent with a previous study of Tonkean macaques (Macaca tonkeana) and brown capuchin monkeys (Cebus apella) suggesting that stimuli of conspecifics and phylogenetically close species do not necessarily provide similar results (Dufour et al., 2006).

(1)

\section{General Discussion}

This study investigated whether capuchin monkeys can categorize conspecific and heterospecific faces based on age. In Experiment 1 we trained four monkeys to 18 


\section{AGE CATEGORIZATION IN CAPUCHIN MONKEY}

386

387

388

389

390

391

392

393

394

395

396

397

398

399

400

401

402

403

404

405

406

407

408

discriminate between adult and infant faces of conspecifics, then tested whether their acquired categorization ability transferred to other species (dogs and humans). In Experiment 2 we trained another two monkeys on age category discrimination of heterospecific (human) faces, and tested transfer to conspecific and dog faces. In Experiment 3, all monkeys were trained on stimuli of a second species, after which they were tested with photos of dogs and other various species. In all experiments, age categorization failed to transfer significantly to different species in the test phase. However, it is noteworthy that during the training phase in three experiments, all monkeys quickly learned to differentiate "adult” and "infant” categories of conspecifics and humans.

The capuchin monkeys in this study learned to categorize conspecific and human faces on the basis of age. In previous studies of nonhuman primates' use of visual information, chimpanzees and rhesus monkeys were shown to visually discriminate between unknown individuals (Parr, Winslow, Hopkins, \& de Waal, 2000), while Japanese macaques can categorize sex of conspecifics (Koba \& Izumi, 2006). It is also known that nonhuman primates can discriminate between faces of other species (Parr, Dove, \& Hopkins, 1998; Parr, Winslow, \& Hopkins, 1999). The results of the present study are not only consistent with previous research, but add age as a category within nonhuman primates’ discrimination abilities; furthermore, this applies to both conspecific and heterospecific (human) faces.

If the categorization established during the training phase was low-level features, we might have expected that many more stimulus pairs would have been necessary to complete the training. Moreover, we used "all reinforcement” for new stimuli during the 


\section{AGE CATEGORIZATION IN CAPUCHIN MONKEY}

409

410

411

412

training phase, meaning that even without feedback the monkeys still responded correctly. The rapid acquisition of categorical learning in training indicates that the discrimination was not based on only low-level features, although we cannot rule out the possibility that it was based on something other than age, for example, "cuteness". Importantly, however, their performance matched the age category, and they extracted shared visual features within each age category immediately during the training. Human raters quite easily correctly recognized the age categories of humans, capuchin monkeys and dogs. However, although the monkeys learned to categorize faces according to age during training, they failed to transfer to other species in the test phase. There are several possible reasons for this failure. First, categorizing age from faces may not be an automatic process. Generalization was tested by probe trials, which investigate spontaneous responses. Given that facial information is not the only available information in daily life, the ability to recognize age-related information and spontaneously categorizing age of faces reflect different things. The former but not the latter was observed in our capuchin monkeys. Second, we trained the monkeys using pictures of two species (humans and capuchins), but training with more species may be required to form species-general age categorization. Finally, monkeys failed to generalize possibly because certain cues used in one species was not available for another species. They did not use species-general features to categorize adults and infants, or there may be no set of common features that distinguish between adult and infant faces across the species we used. If so, we need to be careful before asserting that species-general infantile features like "baby schema” exist across species. 


\section{AGE CATEGORIZATION IN CAPUCHIN MONKEY}

This is because stimuli may include both younger and older infant/adult features as we usually occur in early developmental than in adulthood, there may be greater variety within infant compared to adult stimuli.

In this study we used stationary, grayscale visual stimuli. In their daily life of course monkeys have a much richer array of information available to help them recognize other individuals, including color, body size, motion, vocalizations and odors. For example, infant vocalizations work as releasers of caretaking in common marmosets (Callithrix jacchus) (Barbosa \& Mota, 2014). The impoverished visual stimuli used in our experiments might explain the failures to transfer the acquired discrimination ability to different species. A previous study revealed auditory-visual cross-modal perception in tufted capuchin monkeys (Evans, Howell, \& Westergaard, 2005). These authors simultaneously presented monkeys with two videos of facial expressions along with one vocalization that matched one of the faces. The monkeys preferred to look at the face

448 that matched the vocal stimulus. Age-related recognition should also be possible using cues in auditory or other modalities as well as visual. 


\section{AGE CATEGORIZATION IN CAPUCHIN MONKEY}

454 categorization and clarify the boundary between "adults” and "infants” for monkeys.

455 Future studies should examine both morphological changes with development and the 456 role of such changes in age category recognition in various species.

457 In summary, capuchin monkeys categorized adult and infant faces of both

458 conspecifics and heterospecifics through training, which means they are sensitive to

459 some features which convey age-related information. However, training with stimuli of

460 two species did not result in clear generalization of the age categorization to different

461 species. These results call for reconsideration of the "baby schema” from a comparative 462 perspective. 


\section{AGE CATEGORIZATION IN CAPUCHIN MONKEY}

463

464

465

466

467

468

469

470

471

472

473

474

475

476

477

478

479

480

\section{References}

Adachi, I., \& Fujita, K. (2005). Categorical discrimination of human faces from the other body parts in pigeons. Japanese Journal of Animal Psychology. https://doi.org/10.2502/janip.55.49

Alley, T. R. (1980). Infantile colouration as an elicitor of caretaking behaviour in Old World primates. Primates, 21, 416-429. https://doi.org/10.1007/BF02390470

Alley, T. R. (1981). Head shape and the perception of cuteness. Developmental Psychology, 17(5), 650-654. https://doi.org/10.1037/0012-1649.17.5.650

Alley, T. R. (1983a). Growth-produced changes in body shape and size as determinants of perceived age and adult caregiving. Child Development, 54(1), 241-248.

Alley, T. R. (1983b). Infantile head shape as an elicitor of adult protection. MerrillPalmer Quarterly, 29(4), 411-427.

Almeling, L., Hammerschmidt, K., Sennhenn-Reulen, H., Freund, A. M., \& Fischer, J. (2016). Motivational shifts in aging monkeys and the origins of social selectivity. Current Biology, 26(13), 1744-1749. https://doi.org/10.1016/j.cub.2016.04.066

Barbosa, M. N., \& Mota, M. T. da S. (2014). Do newborn vocalizations affect the behavioral and hormonal responses of nonreproductive male common 


\section{AGE CATEGORIZATION IN CAPUCHIN MONKEY}

marmosets (Callithrix jacchus)? Primates, 55(2), 293-302.

482

https://doi.org/10.1007/s10329-013-0404-0

Bates, D., Mächler, M., Bolker, B., \& Walker, S. (2015). Fitting linear mixed-effects models using lme4. Journal of Statistical Software, 67(1), 51-51.

485 https://doi.org/10.18637/jss.v067.i01

486

Borgi, M., \& Cirulli, F. (2013). Children’s Preferences for Infantile Features in Dogs and Cats. Human-Animal Interaction Bulletin, 1(2), 1-15.

488

Borgi, M., Cogliati-Dezza, I., Brelsford, V., Meints, K., \& Cirulli, F. (2014). Baby schema in human and animal faces induces cuteness perception and gaze

490 allocation in children. Frontiers in Psychology, 5(411).

491 https://doi.org/10.3389/fpsyg.2014.00411

492 Calcutt, S. E., Rubin, T. L., Pokorny, J. J., \& de Waal, F. B. M. (2017). Discrimination 493 of emotional facial expressions by tufted capuchin monkeys (Sapajus apella). Journal of Comparative Psychology, 131(1), 40-49. 


\section{AGE CATEGORIZATION IN CAPUCHIN MONKEY}

496 Dufour, V., Coleman, M., Cambell, R., Petit, O., \& Pascalis, O. (2004). On the speciesspecificity of face recognition in human adults. Current Psychology of Cognition, 22(3), 315-333.

499

Dufour, V., Pascalis, O., \& Petit, O. (2006). Face processing limitation to own species in primates: A comparative study in brown capuchins, Tonkean macaques and humans. Behavioural Processes, 73(1), 107-113.

502 https://doi.org/10.1016/j.beproc.2006.04.006

Evans, T. A., Howell, S., \& Westergaard, G. C. (2005). Auditory-visual cross-modal perception of communicative stimuli in tufted capuchin monkeys (Cebus apella). Journal of Experimental Psychology: Animal Behavior Processes, 31, 399-406. https://doi.org/10.1037/0097-7403.31.4.399

Fox, J., \& Weisberg, S. (2011). An R Companion to Applied Regression. Thousand mcmaster.ca/jfox/Books/Companion biology of the genus Cebus. Cambridge: Cambridge University Press. 


\section{AGE CATEGORIZATION IN CAPUCHIN MONKEY}

512 Fujita, K. (2009). Metamemory in tufted capuchin monkeys (Cebus apella). Animal Cognition, 12(4), 575-585. https://doi.org/10.1007/s10071-009-0217-0

514 Glocker, M. L., Langleben, D. D., Ruparel, K., Loughead, J. W., Gur, R. C., \& Sachser, N. (2009). Baby schema in infant faces induces cuteness perception and motivation for caretaking in adults. Ethology, 115(3), 257-263. https://doi.org/10.1111/j.1439-0310.2008.01603.x

518 Golle, J., Lisibach, S., Mast, F. W., \& Lobmaier, J. S. (2013). Sweet Puppies and Cute Babies: Perceptual Adaptation to Babyfacedness Transfers across Species. PLoS ONE, 8(3), e58248-e58248. https://doi.org/10.1371/journal.pone.0058248

521 Hiramatsu, C., \& Fujita, K. (2015). Visual categorization of surface qualities of materials by capuchin monkeys and humans. Vision Research, 115, 71-82. https://doi.org/10.1016/j.visres.2015.07.006

524 Koba, R., \& Izumi, A. (2006). Sex categorization of conspecific pictures in Japanese monkeys (Macaca fuscata). Animal Cognition, 9(3), 183-191. https://doi.org/10.1007/s10071-006-0020-0

527 Koda, H., Sato, A., \& Kato, A. (2013). Is attentional prioritisation of infant faces unique in humans?: Comparative demonstrations by modified dot-probe task in 


\section{AGE CATEGORIZATION IN CAPUCHIN MONKEY}

monkeys. Behavioural Processes, 98, 31-36.

530

https://doi.org/10.1016/j.beproc.2013.04.013

531 Little, A. C. (2012). Manipulation of infant-like traits affects perceived cuteness of infant, adult and cat faces. Ethology, 118(8), 775-782.

533 https://doi.org/10.1111/j.1439-0310.2012.02068.x

534 Lorenz, K. (1943). Die angeborenen Formen möglicher Erfahrung. Zeitschrift Für Tierpsychologie, 5(2), 235-409. https://doi.org/10.1111/j.1439-

536 0310.1943.tb00655.x

Ottoni, E. B., de Resende, B. D., \& Izar, P. (2005). Watching the best nutcrackers: what capuchin monkeys (Cebus apella) know about others’ tool-using skills. Animal Cognition, 8(4), 215-219. https://doi.org/10.1007/s10071-004-0245-8

540 Parr, L. A., Dove, T., \& Hopkins, W. D. (1998). Why faces may be special: evidence of the inversion effect in chimpanzees. Journal of Cognitive Neuroscience, 10(5), 615-622. https://doi.org/10.1162/089892998563013

543 Parr, L. A., Winslow, J. T., \& Hopkins, W. D. (1999). Is the inversion effect in rhesus monkeys face-specific? Animal Cognition, 2(3), 123-129.

545 https://doi.org/10.1007/s100710050032 


\section{AGE CATEGORIZATION IN CAPUCHIN MONKEY}

546 Parr, L. A., Winslow, J. T., Hopkins, W. D., \& de Waal, F. B. M. (2000). Recognizing facial cues: individual discrimination by chimpanzees (Pan troglodytes) and rhesus monkeys (Macaca mulatta). Journal of Comparative Psychology (Washington, D.C. : 1983), 114(1), 47-60. https://doi.org/10.1037/0735-

550 7036.114.1.47

551

Pascalis, O., de Haan, M., \& Nelson, C. A. (2002). Is face processing species-specific during the first year of life? Science, 296(5571), 1321-1323. https://doi.org/10.1126/science.1070223

Pokorny, J. J., \& de Waal, F. B. (2009). Monkeys recognize the faces of group mates in photographs. Proc Natl Acad Sci U S A, 106(51), 21539-21543.

556 https://doi.org/0912174106 [pii]¥r10.1073/pnas.0912174106

R Core Team. (2013). R: A Language and Environment for Statistical Computing. Vienna, Austria: R Foundation for Statistical Computing. Retrieved from http://www.r-project.org/ generalization of leaf damage by blue jays (Cyanocitta cristata). Animal 


\section{AGE CATEGORIZATION IN CAPUCHIN MONKEY}

563 Sato, A., Koda, H., Lemasson, A., Nagumo, S., \& Masataka, N. (2012). Visual species-specific vs universal cognitive traits in primates. PLoS ONE, 7(5), 1-7. https://doi.org/10.1371/journal.pone.0038387

567

Sternglanz, S. H., Gray, J. L., \& Murakami, M. (1977). Adult preferences for infantile 


\section{AGE CATEGORIZATION IN CAPUCHIN MONKEY}

572

\section{Table}

573 Table1. The overall flow and stimuli used in Experiment 1,2 and 3

\begin{tabular}{|c|c|c|}
\hline Phase & $\begin{array}{l}\text { four monkeys; } \\
\text { Heiji, Zilla, Theta and Zen }\end{array}$ & $\begin{array}{l}\text { two monkeys; } \\
\text { Zinnia and Pigmon }\end{array}$ \\
\hline \multicolumn{3}{|c|}{ Experiment 1} \\
\hline training & conspecific & - \\
\hline test & human and dog & - \\
\hline \multicolumn{3}{|c|}{ Experiment 2} \\
\hline training & - & human \\
\hline Test & - & conspecific and dog \\
\hline \multicolumn{3}{|c|}{ Experiment 3} \\
\hline training & human & conspecific \\
\hline test & \multicolumn{2}{|c|}{$\operatorname{dog}$} \\
\hline test & \multicolumn{2}{|c|}{ various species from four taxonomic groups } \\
\hline
\end{tabular}

574

575 


\section{AGE CATEGORIZATION IN CAPUCHIN MONKEY}

576 Table 2. Summary of the result of logistic analyses for the number of "infant” responses

577 in Test phase during Experiment 1

\begin{tabular}{ccccccccc}
\hline & \multicolumn{2}{c}{ Odds Ratio } & \multicolumn{2}{c}{$p$} & \multicolumn{3}{c}{ 95\% Conf. Interval } \\
\hline Subject & Intercept & age & Intercept & age & Intercept & \multicolumn{2}{c}{ age } \\
\hline Dog & & & & & & & & \\
Heiji & 9.80 & 0.83 & $<.001$ & 0.546 & 5.62 & 18.96 & 0.44 & 1.51 \\
Theta & 2.59 & 0.79 & $<.001$ & 0.240 & 1.77 & 3.87 & 0.53 & 1.17 \\
Zen* & $\mathbf{2 . 0 4}$ & $\mathbf{0 . 5 2}$ & $<.001$ & $\mathbf{0 . 0 0 1}$ & $\mathbf{1 . 4 0}$ & $\mathbf{3 . 0 6}$ & $\mathbf{0 . 3 5}$ & $\mathbf{0 . 7 6}$ \\
Zilla & 2.01 & 0.72 & $<.001$ & 0.094 & 1.39 & 2.95 & 0.50 & 1.05 \\
Human & & & & & & & & \\
Heiji & 14.02 & 1.45 & $<.001$ & 0.309 & 7.36 & 31.72 & 0.73 & 3.21 \\
Theta & 1.37 & 0.94 & 0.078 & 0.720 & 0.97 & 1.96 & 0.66 & 1.33 \\
Zen & 1.67 & 1.14 & 0.005 & 0.466 & 1.17 & 2.41 & 0.80 & 1.64 \\
Zilla & 1.03 & 0.86 & 0.859 & 0.377 & 0.73 & 1.46 & 0.60 & 1.21 \\
\hline
\end{tabular}

578

*Significant result is in bold.

579 
AGE CATEGORIZATION IN CAPUCHIN MONKEY

580 Table 3. GLMM parameter estimate coefficients and confidence interval in Experiment

$581 \quad 1$ and 3.

\begin{tabular}{lcccccc}
\hline Predicter variables & Estimate & SE & $Z$ & $p$ & 95\% Conf. Interval \\
\hline Exp.1 Dog stimuli & & & & & & \\
$\quad$ Intercept) & 1.52 & 0.35 & 4.37 & $<.001$ & 0.84 & 2.2 \\
$\quad$ Infant & $\mathbf{- 0 . 7 5}$ & $\mathbf{0 . 2 1}$ & $-\mathbf{3 . 5 7}$ & $<.001$ & $\mathbf{- 1 . 1 7}$ & $\mathbf{- 0 . 3 4}$ \\
$\quad$ Exp1. Human stimuli & & & & & & \\
$\quad$ Intercept) & 0.84 & 0.50 & 1.67 & 0.10 & -0.15 & 1.82 \\
$\quad$ Infant & $<.001$ & 0.20 & $<.001$ & 1.00 & -0.39 & 0.39 \\
Exp3. Dog stimuli & & & & & & \\
$\quad$ Intercept) & 1.62 & 0.43 & 3.80 & $<.001$ & 0.78 & 2.45 \\
$\quad$ Infant & 0.38 & 0.20 & 1.91 & 0.06 & -0.01 & 0.78 \\
\hline
\end{tabular}

582

*Significant result is in bold.

583 


\section{AGE CATEGORIZATION IN CAPUCHIN MONKEY}

584 Table 4. Summary of the result of logistic analyses for the number of "infant” responses

585 in test phase during Experiment 2

\begin{tabular}{lcccccccc}
\hline & \multicolumn{2}{c}{ Odds Ratio } & \multicolumn{2}{c}{$p$} & \multicolumn{3}{c}{ 95\% Conf. Interval } \\
\hline Subject & Intercept & age & Intercept & age & Intercept & \multicolumn{2}{c}{ age } \\
\hline Dog & & & & & & & & \\
Pigmon & 1.75 & 1.36 & 0.003 & 0.101 & 1.22 & 2.53 & 0.95 & 1.96 \\
Zinnia & 7.05 & 1.15 & $<.001$ & 0.594 & 4.30 & 12.44 & 0.68 & 1.99 \\
Monkey & & & & & & & & \\
Pigmon* & $\mathbf{0 . 6 3}$ & $\mathbf{1 . 4 9}$ & $\mathbf{0 . 0 1 3}$ & $\mathbf{0 . 0 3 1}$ & $\mathbf{0 . 4 3}$ & $\mathbf{0 . 9 0}$ & $\mathbf{1 . 0 4}$ & $\mathbf{2 . 1 6}$ \\
Zinnia & 3.02 & 1.18 & $<.001$ & 0.415 & 2.05 & 4.59 & 0.79 & 1.78 \\
\hline
\end{tabular}

$586 \quad *$ Significant result is in bold.

587

588

589 


\section{AGE CATEGORIZATION IN CAPUCHIN MONKEY}

590 Table 5. GLMM parameter estimate coefficients and confidence interval in Experiment

5913.

\begin{tabular}{lcccccc}
\hline Predicter variables & Estimate & $\mathrm{SE}$ & $Z$ & $p$ & \multicolumn{2}{c}{ 95\% Conf. Interval } \\
\hline (Intercept) & 0.07 & 0.37 & 0.20 & 0.84 & -0.64 & 0.79 \\
Ape vs. New-world & $\mathbf{1 . 8 5}$ & $\mathbf{0 . 4 7}$ & $\mathbf{3 . 9 5}$ & $<.001$ & $\mathbf{0 . 9 3}$ & $\mathbf{2 . 7 7}$ \\
Ape vs. Old-World & $\mathbf{0 . 6 2}$ & $\mathbf{0 . 3 1}$ & $\mathbf{1 . 9 9}$ & $\mathbf{0 . 0 5}$ & $\mathbf{0 . 0 0 8}$ & $\mathbf{1 . 2 2}$ \\
Ape vs. Carnivore & $\mathbf{1 . 1 1}$ & $\mathbf{0 . 2 9}$ & $\mathbf{3 . 8 0}$ & $<.001$ & $\mathbf{0 . 5 4}$ & $\mathbf{1 . 6 8}$ \\
Adult vs. Infant & $\mathbf{1 . 1 5}$ & $\mathbf{0 . 3 3}$ & $\mathbf{3 . 5 4}$ & $<.001$ & $\mathbf{0 . 5 1}$ & $\mathbf{1 . 7 9}$ \\
New-world: Infant & -0.97 & 0.69 & -1.40 & 0.16 & -2.32 & 0.39 \\
Old-World: Infant & -0.23 & 0.48 & -0.48 & 0.63 & -1.16 & 0.71 \\
Carnivore: Infant & $\mathbf{- 0 . 9 1}$ & $\mathbf{0 . 4 3}$ & $\mathbf{- 2 . 0 9}$ & $\mathbf{0 . 0 4}$ & $\mathbf{- 1 . 7 5}$ & $\mathbf{- 0 . 0 6}$ \\
\hline
\end{tabular}

592

*Significant result is in bold. 
AGE CATEGORIZATION IN CAPUCHIN MONKEY

593

594

595

596

597

598

599

600

601

602 Figure 1. Experimental procedure (Symbolic matching to sample task) and examples of

603 stimuli (top: adult capuchin monkey, bottom: infant capuchin monkey)

\section{Figure}

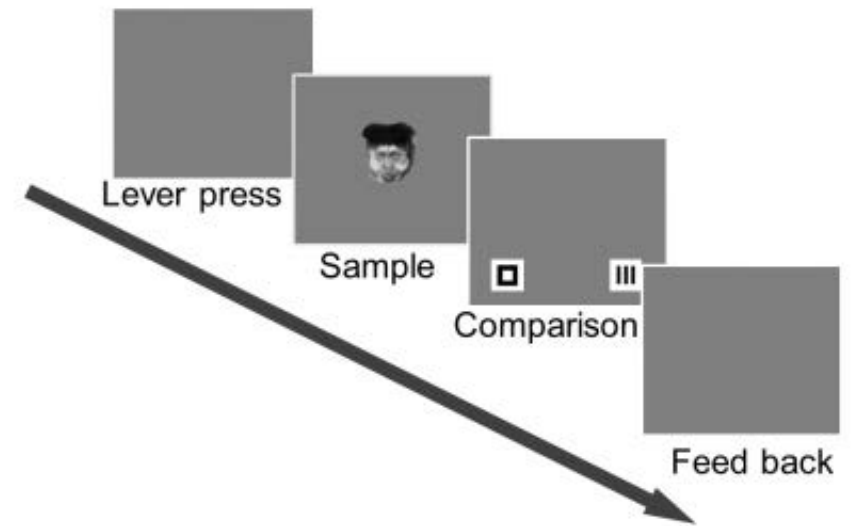

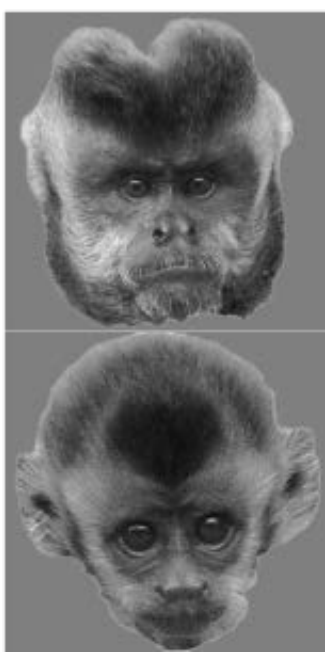

604 


\section{AGE CATEGORIZATION IN CAPUCHIN MONKEY}

605

606

607

608

609

610
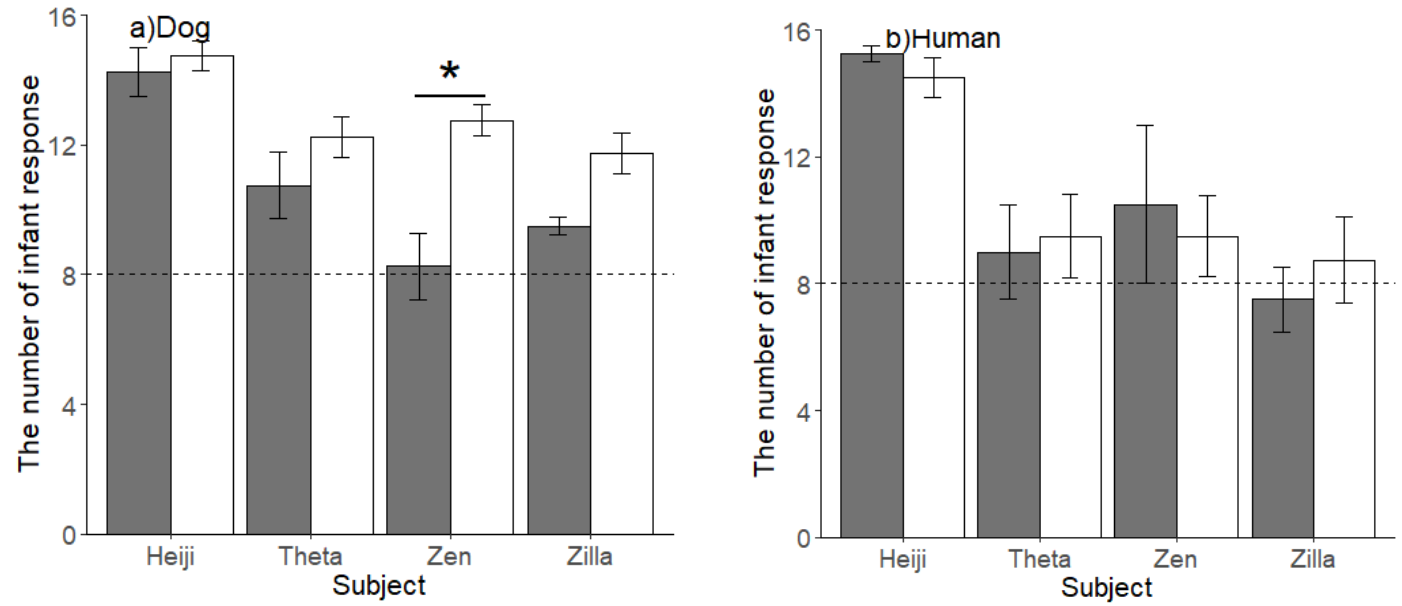

611 age

age $\square$ Infant $\square$ Adult

612 Figure 2. The mean number of "infant” responses in the generalization test for dog

613 stimuli (a) and human stimuli (b) in four monkeys in Experiment 1 . The dotted line

614 represents chance level. The color of bar indicates age category of stimuli. Asterisk

615 indicates significant difference between adult and infant stimuli, $p<.05$. Error bars

616 represent standard errors.

617 


\section{AGE CATEGORIZATION IN CAPUCHIN MONKEY}

618

619

620

621
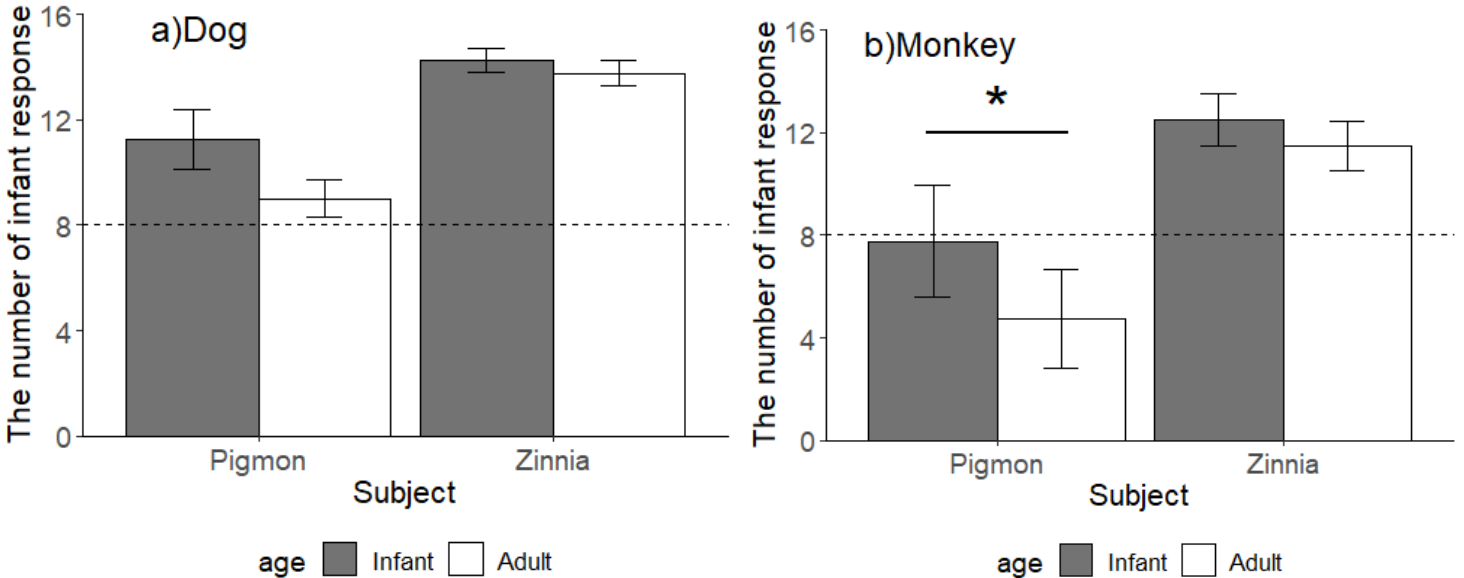

622

age $\square$ Infant

age $\square$ Infant $\square$ Adult

623 Figure 3. The mean number of "infant" responses in the generalization test for dog

624 stimuli (a) and monkey stimuli (b) in two monkeys in Experiment 2. The color of bar

625 indicates age category of stimuli. The dotted line represents chance level. Asterisk

626 indicates significant difference between adult and infant stimuli, $p<.05$. Error bars

627 represent standard errors.

628 


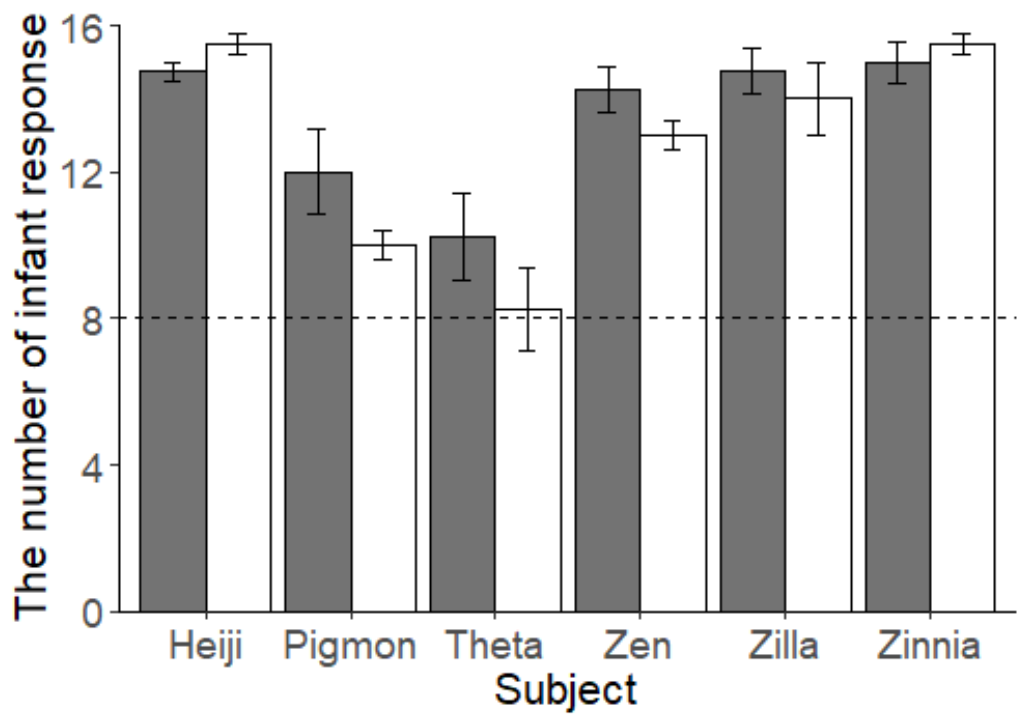

636

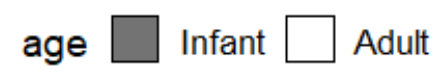

637

638 Figure 4. The mean number of "infant" responses in the generalization test for dog

639 stimuli in all six monkeys in Experiment 3. The color of bar indicates age category of

640 stimuli. The dotted line represents chance level. Error bars represent standard errors. 


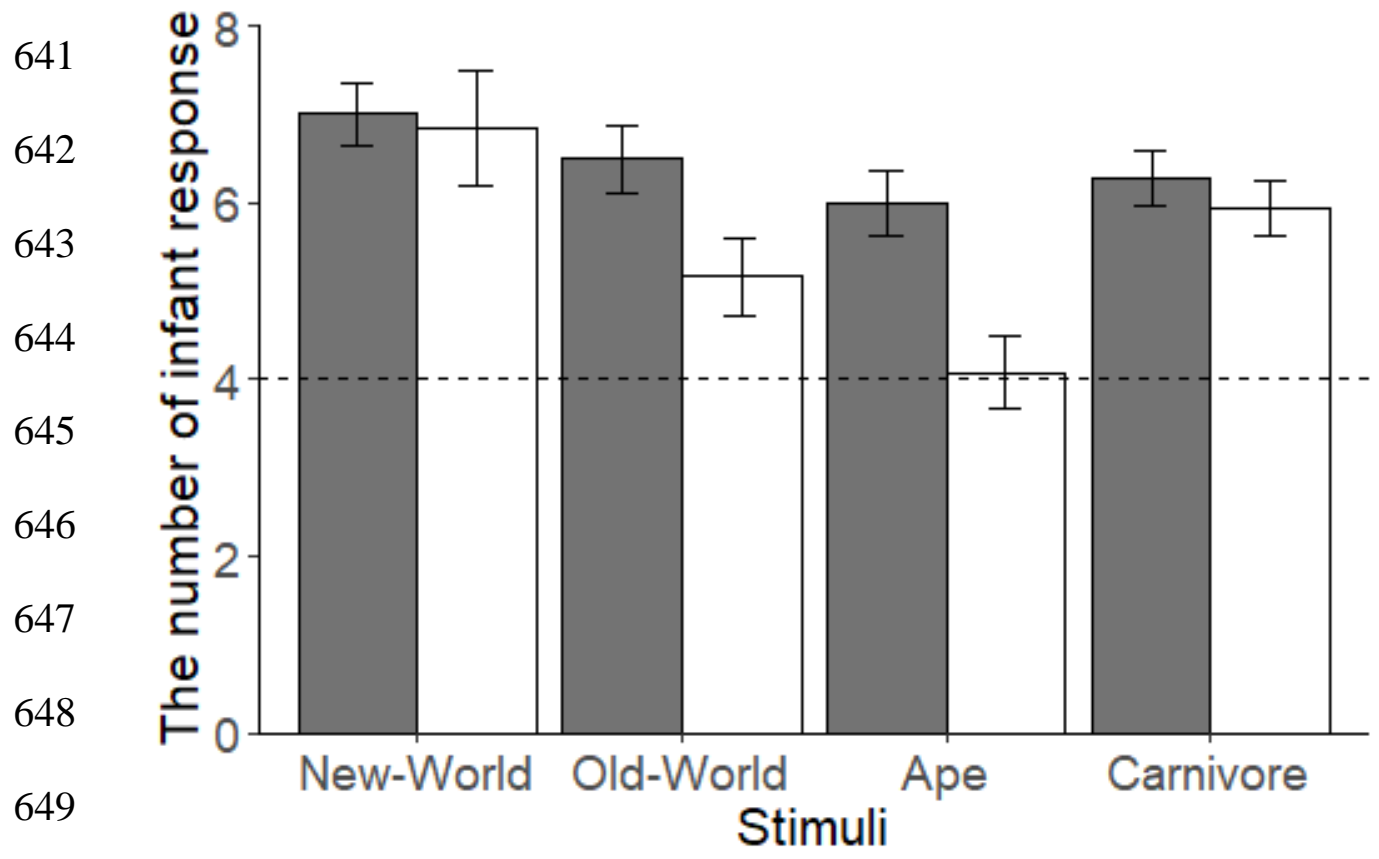

650

651

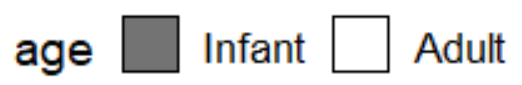

652 Figure 5. The mean number of “infant” responses in the generalization test for various

653 species stimuli (New World monkeys, Old World monkeys, apes and carnivores) in

654 Experiment 3. The dotted line represents chance level. The color of bar indicates age

655 category of stimuli. Error bars represent standard errors.

656 